\title{
Radial growth rate through successive cambia in Haloxylon ammodendron (Chenopodiaceae) from the Gurbantünggüt Desert, Northwestern China, determined by a series of radiocarbon dating
}

\author{
JUNFENG LI, ${ }^{1 *}$ HIDEKI WADA ${ }^{1 * *}$ and HIROYUKI MATSUZAKI ${ }^{2}$ \\ ${ }^{1}$ Graduate School of Science and Technology, Shizuoka University, 836 Oya, Suruga-ku, Shizuoka 422-8529, Japan \\ ${ }^{2}$ Research Center for Nuclear Science and Technology, The University of Tokyo, \\ 2-11-16 Yayoi, Bunkyo-ku, Tokyo 113-0032, Japan \\ (Received June 17, 2014; Accepted August 25, 2014)
}

\begin{abstract}
It is known that Haloxylon has successive cambia and its radial growth rate is not clear as indicated by the fact that the annual boundary cannot be determined by dendrochronological approach. Radial increment through successive cambia (RISC) layers possess similar morphological feature as compared to annual rings by megascopic cross sectional observations. Previous studies have demonstrated that the dendrochronological methods cannot be applied to some species that possess successive cambia. The objective of the present study is to clarify the growth rate of RISC layer in Haloxylon ammodendron by a series of radiocarbon dating. Two H. ammodendron specimens ( 1 and S2) were collected from the southern edge of Gurbantünggüt Desert in Northwestern China. Radiocarbon measurements revealed the numbers of annual RISC layer to be $2.98 \pm 0.51$ (S1) and $3.65 \pm 0.53$ (S2). Linear regression shows a strong relationship between growth period $(x)$ and radial increment accumulation $(y): y=1.52 x+0.76\left(R^{2}=0.96, P<0.001\right)$ for S1 and $y=1.70 x+4.49\left(R^{2}\right.$ $=0.94, P<0.001)$ for S2, respectively. Anatomical observations on the RISC layer using scanning electron microscope (SEM) image showed that: (1) the early wood and late wood were not present or differentiated; (2) axial vessel groups (about 2-10 vessels) are often distributed in the bark-side; and (3) sclerenchyma cells as junctions tightly adhered vessel groups at outside in each RISC layer. These observed features are completely different from those in annual ring morphologies. We tentatively hypothesize that these features are due to the formation of multiple RISC layers within one growing season in order to aid in water storage in the stem to survive in harsh habitat conditions. This research will help further the knowledge in the physiological and ecophysiological researches on H. ammodendron and other successive cambia species.
\end{abstract}

Keywords: Haloxylon ammodendron, radial increment through successive cambia (RISC) layer, radiocarbon dating, radial growth rate, Gurbantünggüt Desert

\section{INTRODUCTION}

Successive cambia are not just an ontogenetic phenomenon (Carlquist, 2001), which are involved in the secondary growth of at least 200 woody species from $>30$ plant families (Robert et al., 2014). Successive cambia look like prolonged phloem longevity, because each of the successive cambia can continue to produce xylem towards the inner part and phloem towards the outer part of the plant stem (Carlquist, 2007). The cambia can literally develop successively and several cambia can also develop simultaneously (Schmitz et al., 2008). Radial increment through successive cambia (RISC) layers in Avicennia

\footnotetext{
*Corresponding author (e-mail: ljfshz@126.com)

**Present address: Institute of Geosciences, Shizuoka University, 836 Oya, Suruga-ku, Shizuoka 422-8529, Japan.
}

Copyright @ 2015 by The Geochemical Society of Japan. marina (A. marina, a grey mangrove species) show a succession of dark colored xylem tissue bands and pale colored phloem tissue bands (Robert et al., 2011). It is difficult to clearly distinguish RISC layers from annual rings, because the RISC layers possess similar morphological features as compared to annual rings through megascopic cross sectional observations (Fig. 1). RISC layer cannot form a complete closed ring but several fragments in a growing season (Robert et al., 2011, 2014; Nazim et al., 2013). Previous studies have demonstrated that the dendrochronological methods cannot be applied to some successive cambia species (Schmitz et al., 2007; Nazim et al., 2013). Santini et al. (2013) used radiocarbon techniques combining with X-ray densitometry to develop a wood density chronology for A. marina in the Exmouth Gulf (from Western Australia), and confirmed that the actual growth rates (range from $4.08 \pm 2.36$ to $5.30 \pm 3.33 \mathrm{~mm} / \mathrm{yr}$ ) were higher than the RISC layer width (range from $0.58 \pm 0.08$ to $0.97 \pm 0.29 \mathrm{~mm} /$ layer) (Santini 

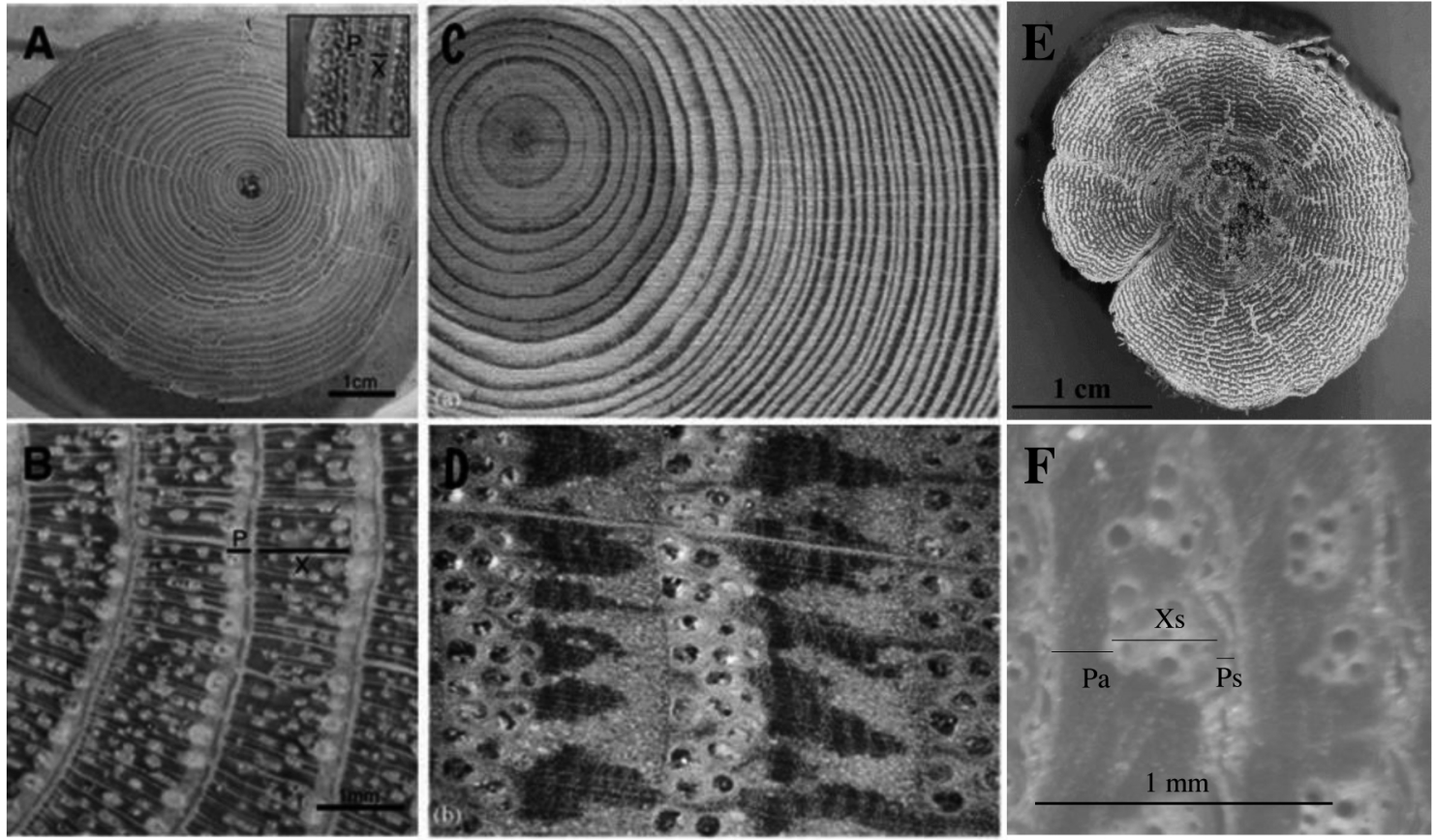

Fig. 1. The RISC layers possess similar morphological feature as compares to annual rings through megascopic cross sectional observations. It is difficult to clearly distinguish RISC layers from annual rings. A. Sanded wood disc of successive cambia species Avicennia marina. Inset shows that the last layers in the wood. B. "Layer" was defined as a complete band of xylem (X) and phloem (P) that is composed of conjunctive tissue including phloem strands (A and B cited from Santini et al., 2012). C. Cross section of a pine tree (seasonal tree ring species) shows the difference in colour (and density) of the early wood and late wood of each ring (@ R. Jalkanen). D. Thin section of oak. Large vessels of the early wood are clearly visible, separated and sometimes offset radially by medullary rays (@ G. Helle) (C and D cited from McCarroll and Loader (2004)). E. A sanded H. ammodendron branch disc from the living specimen (S1) of this study showing the similar morphological (annual ring-like) features. F. Thin section of SI branch. RISC layer was defined as a complete band of secondary xylem (Xs), secondary phloem (Ps) and parenchyma cells $(\mathrm{Pa})$.

et al., 2012). These results indicate that 4-10 RISC layers are formed every year in the A. marina.

Haloxylon Bunge (Chenopodiaceae), a familiar desert plant genus, is a dominant shrub widely distributed in Middle and Central Asia (Liu et al., 2011; Buras et al., 2012), which has many xeromorphic characteristics and plays an important role in the maintenance of the structure and function of the desert ecosystem (Xu et al., 2007; Liu et al., 2011; Buras et al., 2012; Thevs et al., 2013). Over the past century, the Haloxylon vegetation has been logged and utilized as pasture and fuel wood resource, resulting in widespread degradation of the desert ecosystem and desertification (Thevs et al., 2013). Hence, rehabilitation of Haloxylon species is fatal to combat desertification.

Successive cambia were reported in Chenopodiaceae by Carlquist (2001) and Heklau et al. (2012). Heklau et al. (2012) described the wood anatomy in detail and mentioned the maximum number of successive cambia recorded in some annual species of Chenopodiaceae. However, they neither indicated the identification method for determining the maximum successive cambia number nor the annual growing boundary in Haloxylon. The Haloxylon stem shows many alternating tangential xylem/phloem bands (Schweingruber et al., 2006). The radial growth rate is not clear as indicated by the fact that the annual boundary cannot be determined by dendrochronological approach. Xiao et al. (2013) investigated the growth rate of Haloxylon ammodendron $(H$. ammodendron) from the periphery of the Heihe river $\left(41^{\circ} 57^{\prime} \mathrm{N}, 101^{\circ} 03^{\prime} \mathrm{E}, 936 \mathrm{~m}\right.$ a.s.l.) using a cambial pinning method, and indicated the average number of layers formed in six H. ammodendron formed in 2009, 2010 and 2011 as $3.5 \pm 2.1$ (1 to 7 layers); $3.0 \pm 1.7$ ( 1 to 5 layers); and $2.4 \pm 1.1$ ( 1 to 4 layers), respectively. These results show the different RISC layers in individual year. Actually, the unsolved problem can be traced back to the pioneer work over 200 years ago about the Haloxylon age determination (Link, 1807). Radiocarbon $\left({ }^{14} \mathrm{C}\right)$ dating is a powerful dendrochronological dating method (Leavitt and Bannister, 2009) and reported over several decades (Stuiver and Polach, 1977). However, information on a 

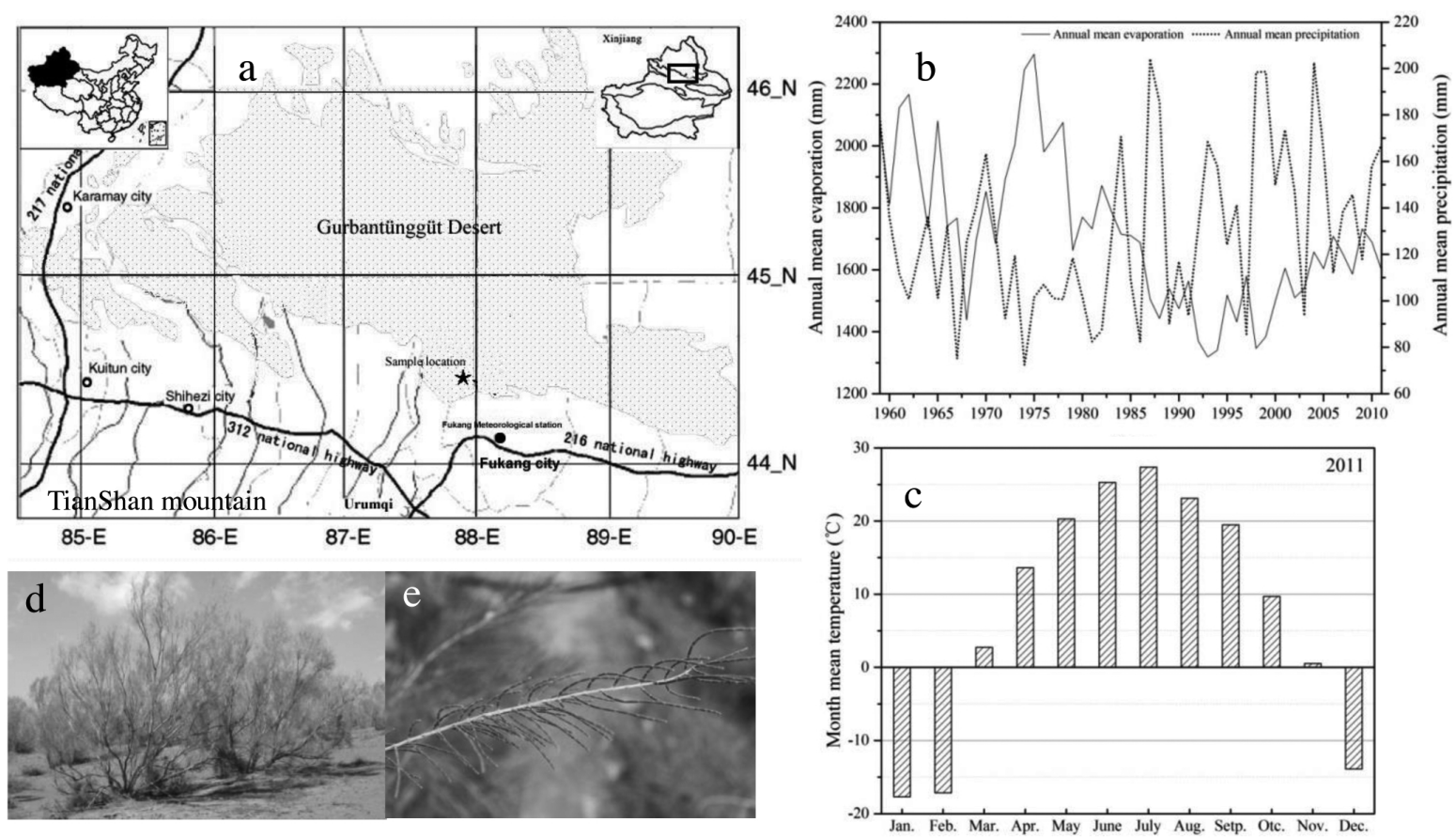

Fig. 2. The geographic map of Gurbantünggüt Desert, sampling location ( $\star$ ) and meteorological station (-) are shown in (a); The annual temperature and evaporation (potential) after 1960 are shown in (b); The month mean temperature of 2011 are shown in (c) (meteorological data source: http://cdc.cma.gov.cn/home.do); H. ammodendron shrub and assimilating shoots in the southern edge of Gurbantünggüt Desert $\left(44^{\circ} 21^{\prime} \mathrm{N}, 87^{\circ} 51^{\prime} \mathrm{E}, 425 \mathrm{~m}\right.$ a.s.l.) are shown in (d) and (e). (Photograph, May 2012).

series of radiocarbon dating in Haloxylon species and other successive cambia species is still lacking.

It has been reported that successive cambia were strongly related to environmental conditions, and that $84.9 \%$ of woody species with concentric internal phloem occurred in dry or saline environments (Robert et al., 2011). H. ammodendron is a stem-succulent shrub in sandy deserts (Song et al., 2006), however, it is in habitat environments with extremely poor growing conditions such as in climates with torrid summers (sandy surface temperatures exceeding $60^{\circ} \mathrm{C}$ ) (Yu et al., 2012), deeper underground water table (Zeng et al., 2012), low frequency of precipitation and high pan evaporation (Xu et $a l ., 2007)$, and high frequency of strong wind and sand storms (Wang et al., 2005). In general, H. ammodendron as a dominant species is able to withstand the harsh environment and store water in its succulent stem, and it may have developed an effective evolutionary strategy and physiological osmotic adjustment traits for preventing water loss. The development of assimilating shoots is one of osmotic adjustment traits demonstrating adaptation to the extreme xeric conditions (Fig. 2e) (Su et al., 2007). Robert et al. (2011) reported the successive cambia as an adaptive structure, but their formation mechanism and elucidating the reason for what triggers their formation are still challenges in wood physiological and ecophysiological researches. Wood anatomical observation can obtain direct information of the radial growth. The characteristics of successive cambia and associated bands have been well described by plant anatomists (Carlquist, 2007; Rajput et al., 2012), but their ecological functions are little discussed. Multiple RISC layers are formed within one growing season in harsh environments, thus it is worth discussing as to whether or not this phenomenon is one of ecological survival strategies for withstanding the environmental stress.

This present research aims to clarify the annual radial growth rate of the RISC layer by a series of radiocarbon measurements on two $H$. ammodendron specimens, and attempts to discuss the formation mechanism and the ecological function of RISC layers by SEM examinations.

\section{Materials ANd Methods}

\section{Sample description}

The Gurbantünggüt desert is located in the Junggar Basin, north of Tianshan Mountain (Fig. 2). This region has a continental arid temperate climate, with a hot, dry summer and cold winter. It has a mean annual temperature of $6.6^{\circ} \mathrm{C}$; mean annual precipitation of approximately $160 \mathrm{~mm}$, with about $40 \%$ of which is distributed in the growing season; pan evaporation is $>2000 \mathrm{~mm}$ (Xu et al., 

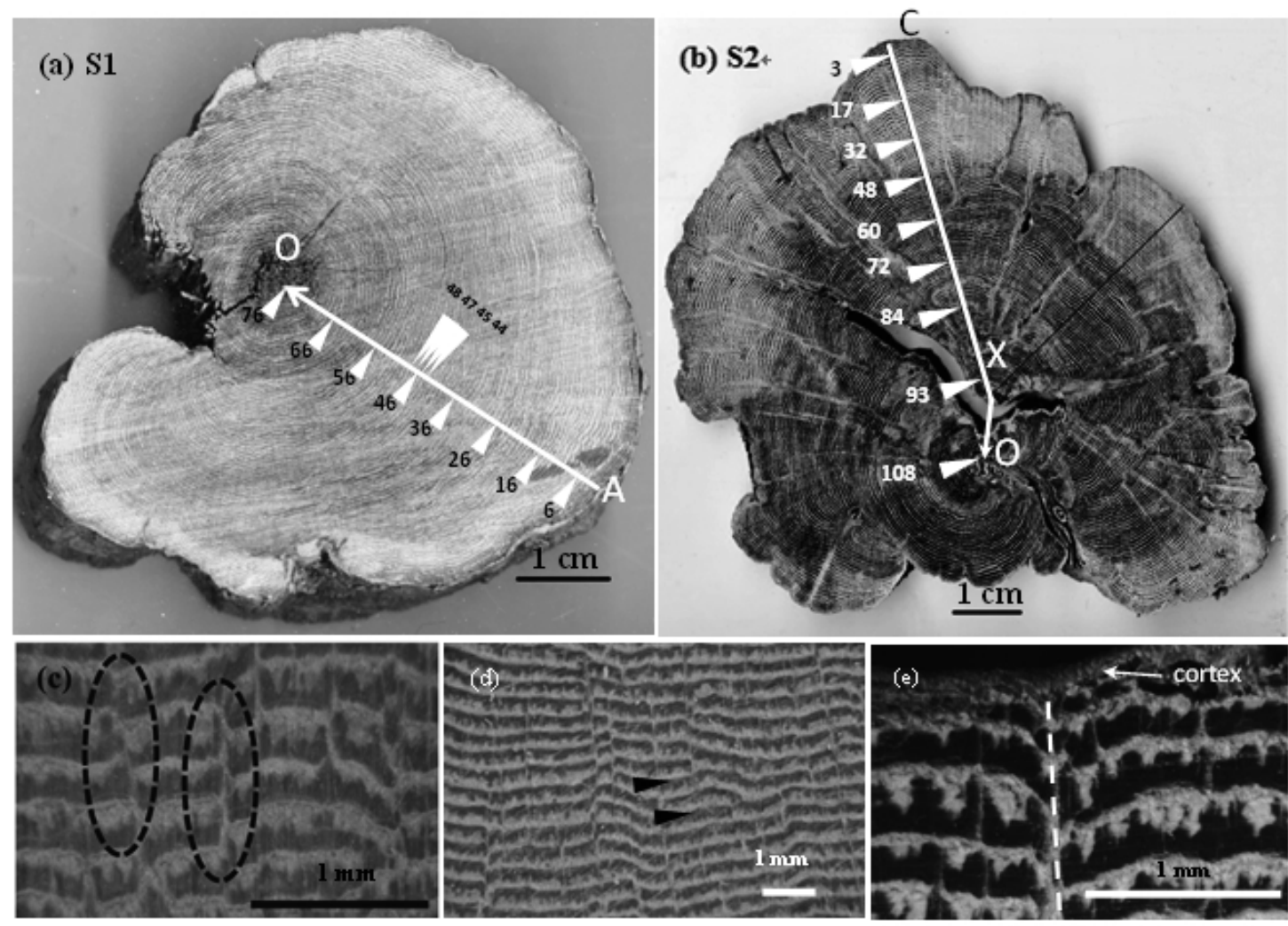

Fig. 3. Cross-sections of H. ammodendron stems from the Gurbantünggüt Desert. The adapted RISC layer for radiocarbon measurements were cut from the positions shown by white triangles: $S 1(a)$ and $S 2(b)$. The adapted RISC layer number and the measured distance from pith were obtained by the cross sectional observation in the radii direction: AO for S1 and CXO for S2. The alternating dark-coloured layers and light-coloured layers were clearly recognized in (c), (d) and (e). Discontinuous RISC layers were frequently observed, shown by the black elliptical dashes in (c), black arrows in (d), and the white dashed line in (e).

2007). In areas of low salinity and deep groundwater table ( $>5 \mathrm{~m}), H$. ammodendron is usually dominant species in the shrub community and exhibits excellent drought resistance and salt tolerance (Song et al., 2006; Xu et al., 2007).

On May 3rd, 2012, two specimens of H. ammodendron (one living: Lab code S1, Fig. 3a and another dead: Lab code $\mathrm{S} 2$, Fig. $3 \mathrm{~b}$ ) were collected in the southern edge of the Gurbantünggüt desert $\left(44^{\circ} 21^{\prime} \mathrm{N}, 87^{\circ} 51^{\prime} \mathrm{E}, 425 \mathrm{~m}\right.$ a.s.l.) for this research. Due to the growing season being from May to the end of September (Xu et al., 2007), the formation time of the outermost layer of the living specimen (S1) was deduced to be 2011 because the sampling time is the beginning period of a new growing season.

\section{Microstructural feature observation}

The adapted RISC layer number in this paper was obtained by the bark-to-pith observation on cross section in the radii direction: $\mathrm{AO}$ for $\mathrm{S} 1$ and $\mathrm{CXO}$ for $\mathrm{S} 2$ (Figs. $3 \mathrm{a}$ and $\mathrm{b}$ ). The 7-cm-diameter living specimen (S1) has 76 RISC layers (Fig. 3a) and the 10-cm-diameter dead specimen (S2) has 108 RISC layers (Fig. 3b). The radial increment accumulation was measured from pith to bark at a precision of $0.01 \mathrm{~mm}$ with the optical microscope (OLYMPUS-BX51). Transverse and tangential sections (approximately $5 \mathrm{~mm}$ in thicknesses) were flattened by a sliding microtome, and then coated with gold/palladium using a sputter coater prior to viewing the microstructural features by a scanning electron microscope (SEM, JSM-6510LV, JEOL).

\section{${ }^{14} \mathrm{C}$ measurement and calibration}

Samples (S) of each RISC layer from S1 and S2 were obtained by careful splitting with a razor knife under a microscope. The $\alpha$-cellulose was extracted from the split tissues using a general method consisting of solvent extraction, bleaching by sodium chlorite solutions and alkali dissolution of hemicellulose (Loader et al., 1997). The $\alpha$-cellulose was combusted in a sealed Pyrex tube with copper (II) oxide $(\mathrm{CuO})$ and silver wire at $550^{\circ} \mathrm{C}$ for 12 hours to produce $\mathrm{CO}_{2}$. The $\mathrm{CO}_{2}$ gas was cryogenically purified by liquid nitrogen $\left(-196^{\circ} \mathrm{C}\right)$ and n-pentane slush 
$\left(-130^{\circ} \mathrm{C}\right)$ using a glass vacuum equipment (Wada and Ito, 1990). Purified $\mathrm{CO}_{2}$ gas was reduced to graphite on catalytic Fe powder using pure hydrogen gas at $635^{\circ} \mathrm{C}$ for 4 hours (Kitagawa et al., 1993).

For standard materials for ${ }^{14} \mathrm{C}$ measurement, we used National Institute of Standard and Technology (NIST) oxalic acid (SRM-4990C) as a standard (NOX, $\delta^{13} \mathrm{C}_{\mathrm{NOX}}$ $=-17.8 \pm 0.47 \%$ ) and SP2 graphite carbon (Nippon Carbon Co. Ltd.) derived from a Japanese coal sample as a secondary in-house standard (BG). In this research, the NOX standard was combusted in a sealed quartz tube with $\mathrm{CuO}$ at $850^{\circ} \mathrm{C}$ for 2 hours to produce $\mathrm{CO}_{2}$. The $\mathrm{BG}$ standard on the other hand was combusted in a sealed quartz tube with $\mathrm{V}_{2} \mathrm{O}_{5}$ at $1000^{\circ} \mathrm{C}$ for 2 hours to produce $\mathrm{CO}_{2}$. The purification and graphitization of $\mathrm{CO}_{2}$, from the standards (NOX and BG), were the same processes as for sample (S) (Wada et al., 1984; Tsuboi et al., 2014). For these graphite samples, ${ }^{12} \mathrm{C},{ }^{13} \mathrm{C}$, and ${ }^{14} \mathrm{C}$ abundances were synchronously measured using an accelerator mass spectrometer (AMS) of the Micro-Analysis Laboratory, University of Tokyo (MALT), Japan (Matsuzaki et al., 2007).

According to Stuiver and Polach (1977), radiocarbon age can be calculated from Eq. (1):

$$
\text { Radiocarbon age }=-\tau \ln F=-8033 \ln \frac{A_{\mathrm{SN}(1950)}}{A_{\mathrm{ON}(1950)}}
$$

Where: the $\tau$ is the Libby mean life (8033 years); $A_{\mathrm{SN}}$ is the specific activity of the sample (As) normalized to $\delta^{13} \mathrm{C}$ $=-25 \% \circ ; A_{\mathrm{ON}}$ is a standard specific activity obtained from the oxalic acid (SRM-4990C, $\delta^{13} \mathrm{C}=-17.8 \%$ ) normalized to $\delta^{13} \mathrm{C}=-25 \%$. AD 1950 equals 0 yrs BP.

To obtain radiocarbon age of the modern woody sample (late 1950s) from measured $\left({ }^{14} \mathrm{C} /{ }^{13} \mathrm{C}\right)$ isotope ratio in this research, the measured values of $\left({ }^{14} \mathrm{C} /{ }^{13} \mathrm{C}\right)_{\mathrm{S}[-17.8]}$ and $\left({ }^{14} \mathrm{C} /{ }^{13} \mathrm{C}\right)_{\text {NOX }[-17.8]}$ needed to be corrected firstly by the measured $\left({ }^{14} \mathrm{C} /{ }^{13} \mathrm{C}\right)_{\mathrm{BG}}$ to eliminate the systematic error, and then subsequently normalized to $\left({ }^{14} \mathrm{C} /{ }^{13} \mathrm{C}\right)_{1950[-25]}$. The fraction of modern $\left(\mathrm{F}^{14} \mathrm{C}\right)$ defined by Reimer et al. (2004) and the radiocarbon age are calculated by the following the formulae (Stuiver, 1983; Linick et al., 1986; Donahue et al., 1990; Reimer et al., 2004):

$$
\begin{aligned}
& \left(\frac{{ }^{14} \mathrm{C}}{{ }^{13} \mathrm{C}}\right)_{\mathrm{S} 1950[-25]}=0.7459 \times\left(\frac{{ }^{14} \mathrm{C}}{{ }^{13} \mathrm{C}}\right)_{\mathrm{S}[-25]} \\
& \left(\frac{{ }^{14} \mathrm{C}}{{ }^{13} \mathrm{C}}\right)_{\mathrm{S}[-25]}=\left(\frac{{ }^{14} \mathrm{C}}{{ }^{13} \mathrm{C}}\right)_{\mathrm{S}[-17.8]}\left(\frac{1-\frac{25}{1000}}{1+\frac{\delta^{13} \mathrm{C}_{\mathrm{S}}}{1000}}\right)
\end{aligned}
$$

$$
\left(\frac{{ }^{14} \mathrm{C}}{{ }^{13} \mathrm{C}}\right)_{\mathrm{NOX} 1950[-25]}=0.7404 \times\left(\frac{{ }^{14} \mathrm{C}}{{ }^{13} \mathrm{C}}\right)_{\mathrm{NOX}[-17.8]}
$$

$$
\begin{aligned}
& \mathrm{F}^{14} \mathrm{C}=\frac{\left(\frac{{ }^{14} \mathrm{C}}{{ }^{13} \mathrm{C}}\right)_{\mathrm{S} 1950[-25]}}{\left(\frac{{ }^{14} \mathrm{C}}{{ }^{13} \mathrm{C}}\right)_{\mathrm{NOX} 1950[-25]}} \\
& =\frac{0.7459 \times\left(\frac{{ }^{14} \mathrm{C}}{{ }^{13} \mathrm{C}}\right)_{\mathrm{S}[-25]}}{\left(\frac{{ }^{14} \mathrm{C}}{{ }^{13} \mathrm{C}}\right)_{\mathrm{NOX} 1950[-25]}} \\
& =\frac{0.7459 \times\left(\frac{1-\frac{25}{1000}}{1+\frac{\delta^{13} \mathrm{C}_{\mathrm{S}}}{1000}}\right)\left(\frac{{ }^{14} \mathrm{C}}{{ }^{13} \mathrm{C}}\right)_{\mathrm{S}[-17.8]}}{0.7404 \times\left(\frac{{ }^{14} \mathrm{C}}{{ }^{13} \mathrm{C}}\right)_{\mathrm{NOX}[-17.8]}}
\end{aligned}
$$

$t=-\tau \ln \left(\mathrm{F}^{14} \mathrm{C}\right)$

where: The subscripts ${ }_{\text {NOx }}$ and ${ }_{S}$ refer to the oxalic acid standard (SRM-4990C) and sample (in this research), respectively. The subscript numbers in square brackets refer to the values which have been normalized to $\delta^{13} \mathrm{C}=$ $-25 \%$ from $\delta^{13} \mathrm{C}=-17.8 \%$. The $t$ is ${ }^{14} \mathrm{C}$ ages.

$\mathrm{F}^{14} \mathrm{C}$ was calibrated using a CALIBomb program (http://calib.qub.ac.uk/CALIBomb/) and the calibration data set (IntCal13) for Zone 1 in the Northern Hemisphere (NH) (Hua and Barbetti, 2004; Hua et al., 2013; Reimer et al., 2013). Errors are expressed as 2 sigma.

Due to the $\mathrm{NH}$ atmospheric ${ }^{14} \mathrm{C}$ concentration which reached a maximum in AD 1963-1964 (Hua, 2009), the $\mathrm{F}^{14} \mathrm{C}$ of the modern woody sample (late 1950s) calibrated by CALIBomb program can be obtained two possible calendar year (cal AD) ranges: T1 (AD 1950-1964) and T2 (late 1964) (Reimer et al., 2004; Hua, 2009), such that the cal AD range of each RISC layer sample in this study was decided through probability comparison and display order number. The outermost layer of S1 was deduced to be 2011, however, that of the dead specimen (S2) could not be determined because it was collected from the dead state, with the date of its death unknown. Furthermore the $\mathrm{NH}$ zone1 data set is only up to 2010 and thus not 
Table 1. Details on the growth periods and radial increment accumulation through radiocarbon $\left(F^{14} C\right)$ dating. Layer No.: RISC layer number from bark of $\mathrm{AO}$ (for $\mathrm{S1}$ ) and CXO (for $\mathrm{S} 2$ ) in Fig. 3; $\mathrm{F}^{14} \mathrm{C}$ : sample radiocarbon data of fraction modern, $S D$ : standard deviation; cal $A D$ : calendar. $A D$ range by $F^{14} C$ dating (2 sigma); P: probability (\%); Age avg: average age of cal $A D$ range; GP: growth period (years); $D$ : distance from pith $(\mathrm{mm})$; RIA: radial increment accumulation from pith $(\mathrm{mm})$.

\begin{tabular}{|c|c|c|c|c|c|c|c|c|c|c|}
\hline Sample & Layer No. & $\mathrm{F}^{14} \mathrm{C}$ & SD & cal AD $(2 \sigma)$ & $P(\%)$ & $\mathrm{Age}_{\mathrm{avg}}$ & GP (yrs) & Error & $\mathrm{D}(\mathrm{mm})$ & RIA (mm) \\
\hline \multirow[t]{43}{*}{ S1 } & 6 & 1.0676 & 0.0097 & $2001.94-2009.52$ & 94.9 & 2005.73 & 23.42 & 3.79 & 37.18 & 35.26 \\
\hline & & & & 2001.21-2001.42 & 1.0 & & & & & \\
\hline & & & & 1956.74-1957.41 & 4.1 & & & & & \\
\hline & 16 & 1.0850 & 0.0083 & 1998.15-2005.23 & 93.3 & 2001.69 & 19.38 & 3.54 & 32.76 & 30.84 \\
\hline & & & & $2005.51-2005.84$ & 1.1 & & & & & \\
\hline & & & & $1956.84-1957.90$ & 5.6 & & & & & \\
\hline & 26 & 1.1128 & 0.0042 & 1994.76-1999.18 & 92.1 & 1996.97 & 14.66 & 2.21 & 27.28 & 25.36 \\
\hline & & & & 1993.84-1994.46 & 2.2 & & & & & \\
\hline & & & & 1999.74-1999.83 & 0.4 & & & & & \\
\hline & & & & $1957.23-1958.10$ & 5.3 & & & & & \\
\hline & 36 & 1.1324 & 0.0119 & 1990.19-1997.79 & 91.9 & 1993.99 & 11.68 & 3.80 & 21.93 & 20.01 \\
\hline & & & & $1957.26-1958.42$ & 8.1 & & & & & \\
\hline & 44 & 1.1308 & 0.0115 & 1990.24-1998.05 & 92.1 & 1994.15 & 11.84 & 3.90 & 17.79 & 15.87 \\
\hline & & & & $1957.26-1958.40$ & 7.9 & & & & & \\
\hline & 45 & 1.1401 & 0.0095 & $1989.91-1995.80$ & 91.2 & 1992.86 & 10.55 & 2.94 & 17.20 & 15.27 \\
\hline & & & & $1957.44-1958.45$ & 8.8 & & & & & \\
\hline & 46 & 1.1474 & 0.0057 & $1989.87-1993.53$ & 90.4 & 1991.70 & 9.39 & 1.83 & 16.72 & 14.80 \\
\hline & & & & $1989.52-1989.53$ & 0.1 & & & & & \\
\hline & & & & 1957.63-1958.49 & 9.5 & & & & & \\
\hline & 47 & 1.1561 & 0.0064 & $1988.82-1992.75$ & 84.6 & 1990.79 & 8.47 & 1.97 & 16.19 & 14.27 \\
\hline & & & & $1957.64-1958.90$ & 15.4 & & & & & \\
\hline & 48 & 1.1637 & 0.0048 & 1987.90-1990.94 & 78.8 & 1989.42 & 7.11 & 1.52 & 15.74 & 13.82 \\
\hline & & & & $1987.14-1987.25$ & 0.6 & & & & & \\
\hline & & & & 1991.60-1991.72 & 0.9 & & & & & \\
\hline & & & & $1957.88-1959.12$ & 19.7 & & & & & \\
\hline & 56 & 1.1908 & 0.0243 & 1982.81-1992.04 & 73.2 & 1987.61 & 5.30 & 4.80 & 11.82 & 9.90 \\
\hline & & & & $1982.50-1982.55$ & 0.1 & & & & & \\
\hline & & & & $1992.39-1992.72$ & 0.4 & & & & & \\
\hline & & & & $1959.76-1961.95$ & 15.1 & & & & & \\
\hline & & & & $1957.86-1959.38$ & 11.2 & & & & & \\
\hline & 66 & 1.2025 & 0.0066 & $1983.90-1987.74$ & 67.1 & 1985.82 & 3.51 & 1.92 & 6.44 & 4.52 \\
\hline & & & & $1959.17-1959.23$ & 2.5 & & & & & \\
\hline & & & & $1959.97-1960.32$ & 16.5 & & & & & \\
\hline & & & & $1960.75-1961.15$ & 15.5 & & & & & \\
\hline & & & & 1961.68-1961.74 & 2.1 & & & & & \\
\hline & 76 & 1.2453 & 0.0021 & $1980.91-1983.71$ & 75.5 & 1982.31 & 0 & 1.40 & 1.92 & 0 \\
\hline & & & & $1980.15-1980.24$ & 0.8 & & & & & \\
\hline & & & & 1984.91-1984.98 & 0.5 & & & & & \\
\hline & & & & $1983.99-1984.08$ & 0.7 & & & & & \\
\hline & & & & $1960.43-1960.54$ & 1.2 & & & & & \\
\hline & & & & $1961.39-1961.64$ & 6.7 & & & & & \\
\hline & & & & $1961.88-1962.02$ & 4.3 & & & & & \\
\hline & & & & $1959.28-1959.82$ & 10.3 & & & & & \\
\hline
\end{tabular}


Table 1. (continued)

\begin{tabular}{|c|c|c|c|c|c|c|c|c|c|c|}
\hline Sample & Layer No. & $\mathrm{F}^{14} \mathrm{C}$ & SD & cal AD $(2 \sigma)$ & $P(\%)$ & $\mathrm{Age}_{\text {avg }}$ & GP (yrs) & Error & $\mathrm{D}(\mathrm{mm})$ & RIA (mm) \\
\hline \multirow[t]{36}{*}{ S2 } & 3 & 1.0631 & 0.0130 & 2001.91-2009.52 & 93.0 & 2005.72 & 28.77 & 3.80 & 53.63 & 51.99 \\
\hline & & & & 2001.10-2001.45 & 1.5 & & & & & \\
\hline & & & & $1956.64-1957.50$ & 5.4 & & & & & \\
\hline & 17 & 1.0891 & 0.0104 & 1996.91-2005.20 & 92.9 & 2001.06 & 24.11 & 4.14 & 45.86 & 44.22 \\
\hline & & & & 2005.52-2005.81 & 0.8 & & & & & \\
\hline & & & & 1996.08-1996.39 & 0.9 & & & & & \\
\hline & & & & 1996.61-1996.63 & 0.1 & & & & & \\
\hline & & & & 1956.87-1957.95 & 5.4 & & & & & \\
\hline & 32 & 1.1084 & 0.0050 & 1995.22-2000.06 & 96.4 & 1997.64 & 20.69 & 2.42 & 38.77 & 37.13 \\
\hline & & & & 1957.30-1957.99 & 3.6 & & & & & \\
\hline & 48 & 1.1340 & 0.0052 & 1991.72-1995.09 & 86.3 & 1993.41 & 16.46 & 1.68 & 34.74 & 33.09 \\
\hline & & & & 1995.62-1995.79 & 1.3 & & & & & \\
\hline & & & & 1990.86-1991.43 & 4.7 & & & & & \\
\hline & & & & 1957.49-1958.34 & 7.7 & & & & & \\
\hline & 60 & 1.1735 & 0.0097 & 1985.80-1990.91 & 79.6 & 1988.36 & 11.41 & 2.56 & 31.87 & 30.22 \\
\hline & & & & 1991.68-1991.70 & 0.1 & & & & & \\
\hline & & & & 1957.96-1959.19 & 20.3 & & & & & \\
\hline & 72 & 1.1859 & 0.0052 & 1985.76-1989.12 & 82.0 & 1987.44 & 10.50 & 1.68 & 27.81 & 26.16 \\
\hline & & & & 1984.96-1985.19 & 1.6 & & & & & \\
\hline & & & & 1958.37-1959.21 & 15.7 & & & & & \\
\hline & & & & 1960.01-1960.28 & 0.5 & & & & & \\
\hline & & & & 1961.03-1961.09 & 0.3 & & & & & \\
\hline & 84 & 1.2258 & 0.0054 & 1982.79-1985.23 & 53.1 & 1984.01 & 7.07 & 1.22 & 21.64 & 20.00 \\
\hline & & & & 1982.22-1982.57 & 1.4 & & & & & \\
\hline & & & & 1985.48-1985.71 & 1.9 & & & & & \\
\hline & & & & 1959.75-1959.99 & 6.8 & & & & & \\
\hline & & & & 1960.30-1961.95 & 32.4 & & & & & \\
\hline & & & & 1959.23-1959.39 & 4.4 & & & & & \\
\hline & 93 & 1.2711 & 0.0116 & $1979.20-1982.63$ & 84.1 & 1980.92 & 3.97 & 1.72 & 8.64 & 7.00 \\
\hline & & & & $1959.38-1959.74$ & 10.3 & & & & & \\
\hline & & & & 1961.43-1961.47 & 0.3 & & & & & \\
\hline & & & & 1961.96-1962.16 & 5.2 & & & & & \\
\hline & 108 & 1.3463 & 0.0068 & 1976.02-1977.87 & 83.6 & 1976.95 & 0.00 & 0.92 & 1.64 & 0 \\
\hline & & & & 1978.38-1978.75 & 8.3 & & & & & \\
\hline & & & & 1974.93-1975.24 & 3.4 & & & & & \\
\hline & & & & $1962.25-1962.36$ & 4.6 & & & & & \\
\hline
\end{tabular}

suitable for the determination of the formation time of the outermost layer by $\mathrm{F}^{14} \mathrm{C}$ dating. The current outermost layer numbers in Table 1 begin from No. 6 (for $\mathrm{S} 1$ ) and No. 3 (for S2).

\section{RESULTS}

\section{Microstructural feature of $\mathrm{H}$. ammodendron}

There are distinct boundaries between RISC layers (Figs. 3c-e and 4a). Each RISC layer mainly composes 3 parts of tissues: secondary xylem (Xs), secondary phloem (Ps) and parenchyma cells (Pa) (Figs. 1f, $4 \mathrm{~b}$ and $4 \mathrm{c}$ ). Some obvious features of RISC layers were easily observed in the two specimens: (1) the layers do not usually coincide with a geometrical centre, as is easily seen with the "eccentric" pith positions (Figs. 3a and b); (2) discontinuous RISC layers were frequently encountered (Figs. 3c-e and 4a); (3) RISC layers consist of alternating patterns of dark layers and light layers, as is clearly seen (Figs. 3c-e); (4) normal early wood and late wood are not present and these are observed as absent (Figs. 4a and b); (5) sclerenchyma cells as junctions tightly adhered vessel groups on the outside portion in each RISC layer in both specimens (Figs. 4b, c, e and f); (6) in a single RISC layer, steep radial and axial vessel groups (about 2-10 vessels) are often distributed in the bark-side (Figs. $4 \mathrm{a}$ and b), the 


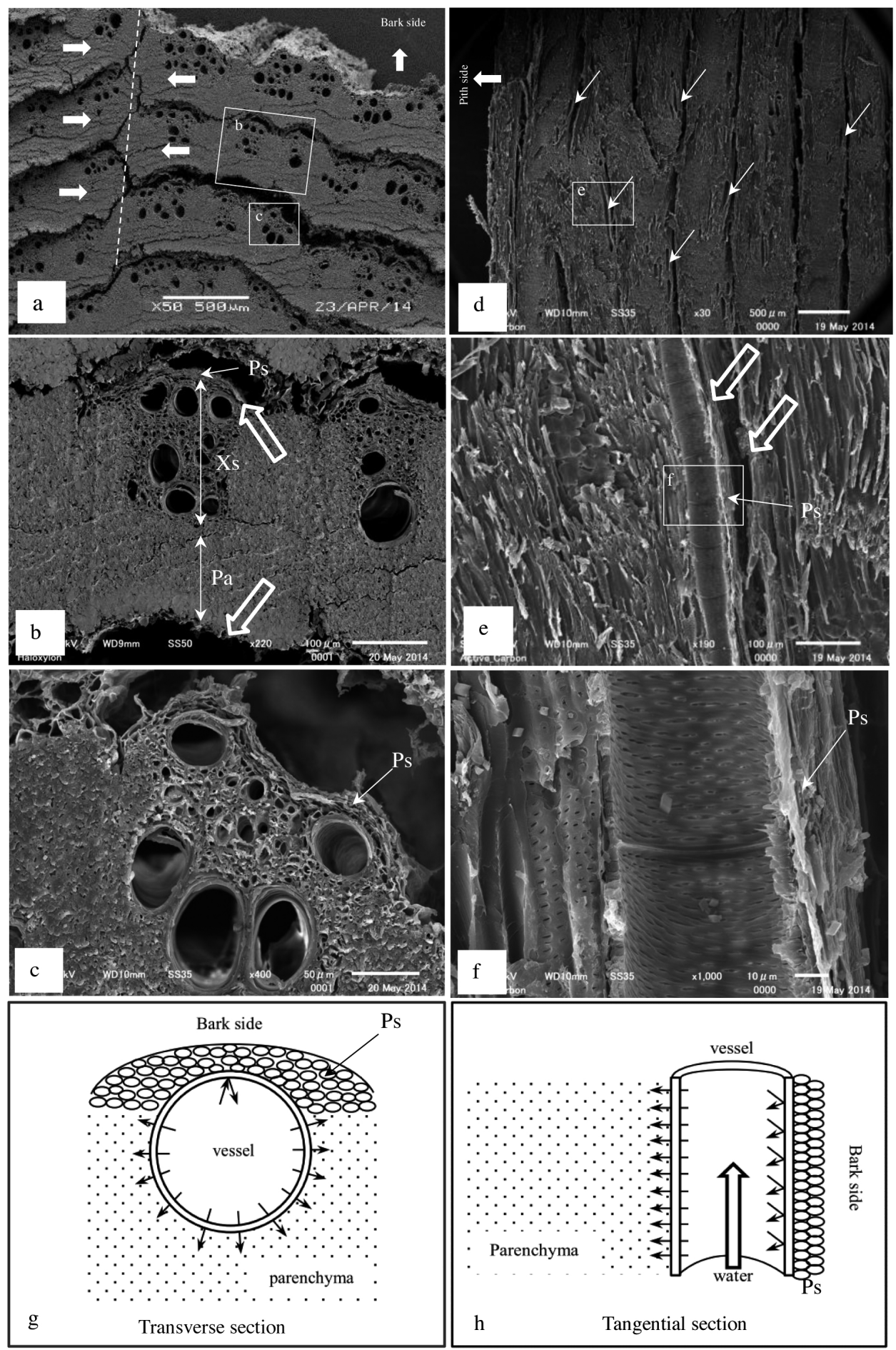

Fig. 4. SEM images of transverse $(a-c)$ and tangential section $(d-f)$ of H. ammodendron stems. (a) Discontinuous RISC layers shown by thick white arrows and white dashed line showing the discontinuity. (b) and (e) Difference in thickness between the bark and pith sides in a single RISC layer, shown by white hollow arrows. Relatively thick-walled secondary phloem fibres encompassing vascular bundles only towards the bark side in the layer, and sclerenchyma cells as junctions tightly adhered vessel groups on the outside in each RISC layer. $(c)$ and $(f)$ magnified enclosed portions in $(a)$ and $(e)$, respectively. $(g)$ and $(h)$ Diagrammatic representations of water movement in a single vessel: the osmotic water movement directions are shown by black thin arrows whiles the normal water flowing direction is shown by a black hollow arrow in (h). The water moves easily from the vessel to the inner (pith side) parenchyma but hardly penetrates to the outer (bark side) secondary phloem fibres and sclerenchyma cells layer which behave like a cell screen to prevent water loss. 

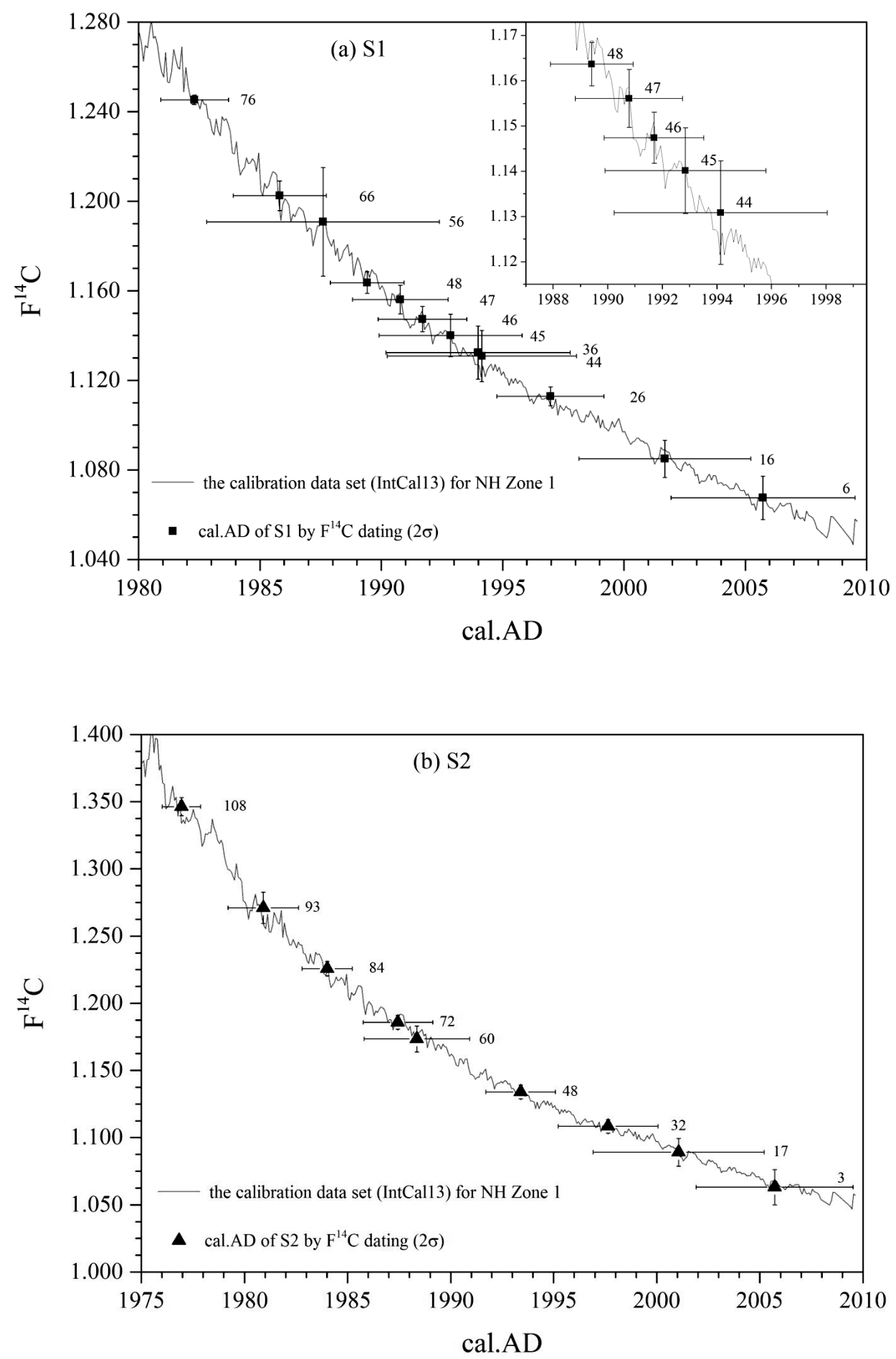

Fig. 5. Calibrated radiocarbon results $\left(F^{14} C\right)$ of the two H. ammodendron specimens. (a) S1: The observed RISC layer numbers were obtained at 10-layers intervals (from No. 6 to No. 76); and 5 continuous layers (from No. 44 to No. 48), in the inset. (b) S2: observed RISC layer numbers were obtained at 10-15 layers intervals (from No. 3 to No. 108). The attached numbers represent the RISC layer number in (a) and (b), which correspond to those shown in Figs. 3(a) and (b), respectively. Errors are expressed as $2 \sigma$. 


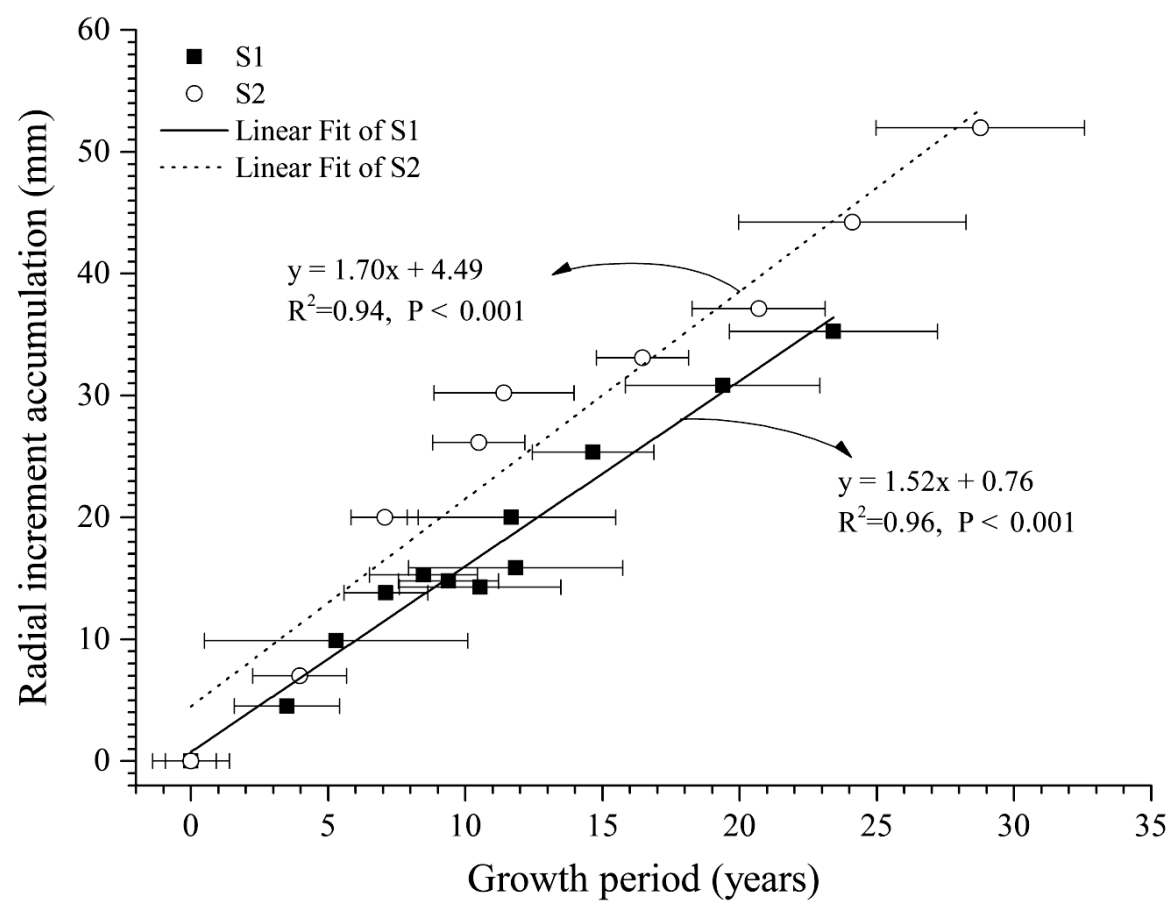

Fig. 6. Linear regression shows a strong relationship between growth period and radial increment accumulation. Radial increment accumulations were calculated by the measured RISC layer distance from the pith: AO for S1 and CXO for S2 (see Fig. 3). The growth period was calculated using the average cal AD year by $F^{14} C$ dating (see Table 1 ). The pith layers were assumed to be zero (0) years for the two specimens.

thickness and structure are different between the barkside band and the pith-side (Fig. 4b). These special anatomical features are completely different from what is observed in a normal annual ring morphologies (Speer, 2010).

\section{${ }^{14} \mathrm{C}$ dating and radial growth rate}

In general, the layer display order numbers show that the inner layer is older than outer layer in a wood disc. The $\mathrm{F}^{14} \mathrm{C}$ results show decreasing from the inner RISC layer number to the outer portions of the two specimens, we deduced that their calendar years are distributed in the T2 period (late 1964). The decided cal AD of each RISC layer through probability comparison, all radiocarbon data is summarized in Table 1. The outermost layer formation time of $\mathrm{S} 1$ is 2011. If each RISC layer were an annual growing layer, then the cal AD years of 5 continuous layers (No. 44 to 48 ) should closely approach the bomb-pulse peak period (approximate 1963-1967) (Hua and Barbetti, 2004; Hua, 2009). However, $\mathrm{F}^{14} \mathrm{C}$ dating results show that they are not annual as indicated by the ages of these 5 continuous layers with AD 1989.42 to 1994.15 (inset of Fig. 5a). This shows that the RISC layer is not an annual growing layer.

According to the $\mathrm{F}^{14} \mathrm{C}$ dating results, the cal $\mathrm{AD}$ years for S1: the pith layer (No. 76) grew between AD 1980.91 to 1983.71 (average: $1982.31 \pm 1.40$ ) and the outer layer (No. 6) grew between AD 2001.94 to 2009.52 (average: $2005.73 \pm 3.79$ ). It has been deduced that the growth span is $23.42 \mathrm{yrs}$, the RISC layer annual formation number is $2.98 \pm 0.51$ and the radial growth rate is $1.51 \mathrm{~mm} \mathrm{yr}^{-1}$ between the two layers (No. 6 and No. 76) in Fig. 5a and Table 1. The cal AD years for S2: the pith layer (No. 108) grew between AD 1976.02 to 1977.87 (average: 1976.95 \pm 0.92 ) and the outer layer (No. 3) grew between AD 2001.91 to 2009.52 (average: $2005.72 \pm 3.80$ ). It has been deduced that the growth span is $28.77 \mathrm{yrs}$, the RISC layer annual formation number is $3.65 \pm 0.53$ and the radial growth rate is $1.81 \mathrm{~mm} \mathrm{yr}^{-1}$ between the two layers (No. 3 and No. 108) in Fig. 5b and Table 1.

Linear regression shows a strong relationship between growth period and radial increment accumulation (Fig. 6):

$$
\begin{aligned}
& \text { S1: } y=1.52 x+0.76\left(R^{2}=0.96, P<0.001\right) \\
& \text { S2: } y=1.70 x+4.49\left(R^{2}=0.94, P<0.001\right)
\end{aligned}
$$

where: $x$ is the growth period (years), the period indicates that the cal AD years between the RISC layer and the pith layer; $y$ is radial increment accumulation $(\mathrm{mm})$, the value indicates that the distance between the RISC 
layer and the pith layer (No. 76 for S1 and No. 108 for S2).

\section{DISCUSSION}

According to the $\mathrm{F}^{14} \mathrm{C}$ dating results, we affirmatively concluded that approximate 3 RISC layers were formed within one growing season in the two $H$. ammodendron specimens. But this phenomenon is hardly understood or explained by seasonal tree growth mechanism (Speer, 2010). H. ammodendron as a stem-succulent and dominant shrub species is widely distributed in desert environments, and it must have special anatomical traits or possess superexcellent ability to store water in its stem tissue to survive in the harsh desert environments. Generally, water loss in secondary plant bodies is not only through the stomata of leaves, but also through the lenticels in the cortex of the stems which support the vital gases exchange (including water vapour) (Lendzian, 2006). The assimilating shoots of $H$. ammodendron show a number of degenerative features for reducing the photoactive area and decreasing plant water loss ( $\mathrm{Su}$ et al., 2007), thus it is worth discussing whether its stem also possesses some features for preventing water loss. In a single $H$. ammodendron RISC layer, the thickness and structure in the bark side band is different from that in the pith side band (Fig. 4b). Axial vessel groups (about 2-10 vessels) are often distributed in the bark-side (Figs. $4 \mathrm{a}$ and d). Secondary phloem and sclerenchyma cells as junctions tightly adhere vessel groups on the outside (Figs. $4 \mathrm{~b}, \mathrm{c}$, e and f). Internal secondary phloem through successive cambia has been suggested to play a role in water storage in a mangrove species (Robert et al., 2011). So we tentatively hypothesize that these special anatomical features of RISC layers in $H$. ammodendron will play a role to store water in the stem. Water moves easily from vessels to the inner (pith side) parenchyma through pit aperture, but hardly penetrates the outer (bark side) secondary phloem fibres and sclerenchyma cells which appear to be a cell screen to prevent water loss (Figs. $4 \mathrm{~g}$ and $\mathrm{h}$ ).

Rajput et al. (2012) described the formation process of successive cambia in Gallesia integrifolia (Phytolaccaceae) as follows: the parenchyma cells located between primary phloem and pericycle fibres become meristematic and form a group of cells arranged in radial rows like cambium by redifferentiation. The cells positioned on the inner side of the newly formed cambium may divide further or differentiate directly into conjunctive tissue from the meristematic bands. Cells on the outer side of the meristematic bands act as a new successive cambia.

In this research, the RISC layer annual formation numbers of the two specimens are $\geq 3$. This means that the meristematic parenchyma cells divide more than 3 times within one growing season. So we tentatively hypothesize that the trigger for meristematic parenchyma cell division in successive cambia is for maximum water storage in the stem within a growing season. Zhu and Jia (2011) demonstrated the effective utilizable water resource for those of over-20-years old $H$. ammodendron is ground water by $\delta^{18} \mathrm{O}$ analysis. In case $H$. ammodendron were exposed to extreme drought or ground water table continuously decreasing for long duration within one growing season, its meristematic cells in successive cambia will be divided into more meristematic bands for maximum water storage in the stem tissue to survive in the harsh desert environments.

For H. ammodendron, multiple RISC layers are formed in one growing season in harsh environments and may be one of the ecological survival strategies for conquering environmental stress. However, the formation mechanism and ecological function of the RISC layer in $H$. ammodendron and other species are still need to be explored further.

\section{CONCLUSIONS}

A series of radiocarbon measurements on two $H$. ammodendron specimens demonstrate that the RISC layer annual formation numbers are $2.98 \pm 0.51$ (for $\mathrm{S} 1$, a live specimen) and $3.65 \pm 0.53$ (for $\mathrm{S} 2$, a dead specimen). A relationship between growth period $(x)$ and radial increment accumulation (y) was determined to be: $y=1.52 x+$ $0.76\left(R^{2}=0.96, P<0.001\right)$ for $\mathrm{S} 1$; and $y=1.70 x+4.49$ $\left(R^{2}=0.94, P<0.001\right)$ for S2. Multiple RISC layers are formed in one growing season in harsh environments which may be for the benefit of the storage of water in the stem and in order to conquer environmental stress. This research will help forward the further physiological and ecophysiological research on $H$. ammodendron and other successive cambia species.

Acknowledgments-We are grateful to Dr. T. T. Hang and T. Tsuboi for discussions on samples preparation. We are also grateful to Mrs. Y. S. Tsuchiya and Dr. H. Kusuno of University of Tokyo for radiocarbon measurement. We are also grateful to Prof. T. Mieno and Dr. D. D. Le for SEM analyses. We are also grateful to Dr. D. Greenidge for valuable comments and English editing. We appreciate the financial support of the Japan Science and Technology Environmental Leadership Program (Grant No. 016100012) of Shizuoka University, Japan. We thank H. A. Takahashi and an anonymous reviewer for their thoughtful comments.

\section{REFERENCES}

Buras, A., Wucherer, W., Zerbe, S., Noviskiy, Z., Muchitdinov, N., Shimshikov, B., Zverev, N., Schmidt, S., Wilmking, M. 
and Thevs, N. (2012) Allometric variability of Haloxylon species in Central Asia. Forest Ecology and Management 274, 1-9.

Carlquist, S. (2001) Comparative Wood Anatomy: Systematic, Ecological, and Evolutionary Aspects of Dicotyledon Wood. Springer, $448 \mathrm{pp}$.

Carlquist, S. (2007) Successive cambia revisited: ontogeny, histology, diversity, and functional significance. J. Torrey Bot. Soc. 134, 301-332.

Donahue, D., Linick, T. and Jull, A. (1990) Isotope-ratio and background corrections for accelerator mass spectrometry radiocarbon measuments. Radiocarbon 32, 135-142.

Heklau, H., Gasson, P., Schweingruber, F. and Baas, P. (2012) Wood anatomy of Chenopodiaceae (Amaranthaceae S.L.). Iawa J. 33, 205-232.

Hua, Q. (2009) Radiocarbon: A chronological tool for the recent past. Quat Geochronol. 4, 378-390.

Hua, Q. and Barbetti, M. (2004) Review of tropospheric bomb ${ }^{14} \mathrm{C}$ data for carbon cycle modeling and age calibration purposes. Radiocarbon 46, 1273-1298.

Hua, Q., Barbetti, M. and Rakowski, A. Z. (2013) Atmospheric radiocarbon for the period 1950-2010. Radiocarbon 55, 2059-2072.

Kitagawa, H., Masazawa, T., Nakamura, T. and Matsumoto, E. (1993) A batch preparation method for graphite targets with low background for AMS ${ }^{14} \mathrm{C}$ measurements. Radiocarbon 35, 295-300.

Leavitt, S. W. and Bannister, B. (2009) Dendrochronology and radiocarbon dating: The laboratory of tree-ring research connection. Radiocarbon 51, 373-384.

Lendzian, K. J. (2006) Survival strategies of plants during secondary growth: barrier properties of phellems and lenticels towards water, oxygen, and carbon dioxide. J. Exp. Bot. 57, 2535-2546.

Linick, T., Jull, A., Toolin, L. and Donahue, D. (1986) Operation of the NSF-Arizona accelerator facility for radioisotope analysis and results from selected collaborative research projects. Radiocarbon 28, 522-533.

Link, H. F. (1807) Grundlehren der anatomie und physiologie der pflanzen. Nadu Press, 472 pp. (in German).

Liu, J. L., Wang, Y. G., Yang, X. H. and Wang, B. F. (2011) Genetic variation in seed and seedling traits of six Haloxylon ammodendron shrub provenances in desert areas of China. Agrofor. Syst. 81, 135-146.

Loader, N. J., Robertson, I., Barker, A. C., Switsur, V. R. and Waterhouse, J. S. (1997) An improved technique for the batch processing of small wholewood samples to $\alpha$ cellulose. Chem. Geol. 136, 313-317.

Matsuzaki, H., Nakano, C., Tsuchiya, Y., Kato, K., Maejima, Y., Miyairi, Y., Wakasa, S. and Aze, T. (2007) Multinuclide AMS performances at MALT. Nuclear Instruments and Methods in Physics Research Section B: Beam Interactions with Materials and Atoms 259, 36-40.

McCarroll, D. and Loader, N. J. (2004) Stable isotopes in tree rings. Quater. Sci. Rev. 23, 771-801.

Nazim, K., Ahmed, M., Shaukat, S. S., Khan, M. U. and Ali, Q. M. (2013) Age and growth rate estimation of grey mangrove Avicennia Marina (Forsk.) vierh from Pakistan. Pak. J. Bot. 45, 535-542.
Rajput, K. S., Romeiro, D., Longui, E. L. and Marcati, C. R. (2012) Development of successive cambia and structure of wood in Gallesia integrifolia (Spreng.) Harms (Phytolaccaceae). Trees-Struct Funct. 26, 1943-1950.

Reimer, P. J., Brown, T. A. and Reimer, R. W. (2004) Discussion: reporting and calibration of post-bomb ${ }^{14} \mathrm{C}$ data. $R a$ diocarbon 46, 1299-1304.

Reimer, P. J., Bard, E., Bayliss, A., Beck, J. W., Blackwell, P. G., Ramsey, C. B., Buck, C. E., Cheng, H., Edwards, R. L. and Friedrich, M. (2013) IntCal13 and Marine13 radiocarbon age calibration curves 0-50,000 years cal BP. Radiocarbon 55, 1869-1887.

Robert, E. M. R., Schmitz, N., Boeren, I., Driessens, T., Herremans, K., De Mey, J., Van de Casteele, E., Beeckman, H. and Koedam, N. (2011) Successive cambia: A developmental oddity or an adaptive structure? Plos One 6, 1-10.

Robert, E. M. R., Jambia, A. H., Schmitz, N., De Ryck, D. J. R., De Mey, J., Kairo, J. G., Dahdouh-Guebas, F., Beeckman, H. and Koedam, N. (2014) How to catch the patch? A dendrometer study of the radial increment through successive cambia in the mangrove Avicennia. Ann. Bot. 113, 741-752.

Santini, N., Schmitz, N. and Lovelock, C. (2012) Variation in wood density and anatomy in a widespread mangrove species. Trees 26, 1555-1563.

Santini, N. S., Hua, Q., Schmitz, N. and Lovelock, C. E. (2013) Radiocarbon dating and wood density chronologies of mangrove trees in arid Western Australia. Plos One 8, 1-8.

Schmitz, N., Verheyden, A., Kairo, J. G., Beeckman, H. and Koedam, N. (2007) Successive cambia development in Avicennia marina (Forssk.) Vierh. is not climatically driven in the seasonal climate at Gazi Bay, Kenya. Dendrochronologia 25, 87-96.

Schmitz, N., Robert, E. M. R., Verheyden, A., Kairo, J. G., Beeckman, H. and Koedam, N. (2008) A patchy growth via successive and simultaneous cambia: Key to success of the most widespread mangrove species Avicennia marina? Ann. Bot. 101, 49-58.

Schweingruber, F. H., Bèorner, A. and Schulze, E.-D. (2006) Atlas of Woody Plant Stems: Evolution, Structure, and Environmental Modifications. Springer, 229 pp.

Song, J., Feng, G., Tian, C.-Y. and Zhang, F.-S. (2006) Osmotic adjustment traits of Suaeda physophora, Haloxylon ammodendron and Haloxylon persicum in field or controlled conditions. Plant Sci. 170, 113-119.

Speer, J. H. (2010) Fundamentals of Rree Ring Research. University of Arizona Press, $333 \mathrm{pp}$.

Stuiver, M. (1983) International agreements and the use of the new oxalic acid standard. Radiocarbon 25, 793-795.

Stuiver, M. and Polach, H. A. (1977) Discussion; reporting of ${ }^{14} \mathrm{C}$ data. Radiocarbon 19, 355-363.

Su, P., Cheng, G., Yan, Q. and Liu, X. (2007) Photosynthetic regulation of $\mathrm{C}_{4}$ desert plant Haloxylon ammodendron under drought stress. Plant Growth Regul. 51, 139-147.

Thevs, N., Wucherer, W. and Buras, A. (2013) Spatial distribution and carbon stock of the Saxaul vegetation of the winter-cold deserts of Middle Asia. J. Arid Environ. 90, 2935.

Tsuboi, T., Wada, H., Nakamura, T., Hang, T. T., Matsuzaki, 
H., Otsuji, N., Fujioka, K., Oguri, K. and Kitazato, H. (2014) Deep-sea limestone block as a source of ${ }^{14} \mathrm{C}$-depleted dissolved inorganic carbon at the Palau Trench. Chem. Geol. 364, $1-8$.

Wada, H. and Ito, R. (1990) Stable isotope analysis of small amount of carbon dioxide and its application to the microscale isotopic zoning of graphite crystals in metamorphic rocks. J. Mass Spectrom. Soc. Japan 38, 287-294.

Wada, H., Fujii, N. and Niitsuma, N. (1984) Analytical method of stable isotope for ultra-small amounts of carbon dioxide with MAT-250 mass spectrometer. Geoscience Reports of Shizuoka Univ. 10, 103-112.

Wang, X., Wang, T., Jiang, J. and Zhao, C. (2005) On the sand surface stability in the southern part of Gurbantünggüt Desert. Science in China Series D: Earth Sciences 48, 778785.

Xiao, S. C., Xiao, H. L. and Peng, X. M. (2013) Tree rings of saxoul (Haloxylon ammodendron) are not suitable for the dendrochronological studies. J. Desert Res. 33, 1692-1698 (in Chinese with English abstract).

Xu, H., Li, Y., Xu, G. and Zou, T. (2007) Ecophysiological response and morphological adjustment of two Central Asian desert shrubs towards variation in summer precipitation. Plant Cell Environ. 30, 399-409.

Yu, T., Ren, C., Zhang, J. P., He, X. L., Ma, L., Chen, Q. J., Qu, Y. Y., Shi, S. B., Zhang, H. and Ma, H. (2012) Effect of high desert surface layer temperature stress on Haloxylon ammodendron (C.A. Mey.) Bunge. Flora. 207, 572-580.

Zeng, Y. L., Liu, T., Zhang, W. B. and Sun, Q. M. (2012) Variations in groundwater levels and quality and their effects on vegetation in the western Grurbantonggut Desert. Acta Ecologica Sinica 32, 1490-1501 (in Chinese with English abstract).

Zhu, Y. and Jia, Z. (2011) Soil water utilization characteristics of Haloxylon ammodendron plantation with different age during summer. Acta Ecologica Sinica 31, 341-346. 